\title{
Docility as a Primary Virtue in Scientific Research
}

\author{
Louise Bezuidenhout ${ }^{1,2}$ - Emanuele Ratti $^{3}$. \\ Nathaniel Warne $^{3}$. Dori Beeler ${ }^{3}$
}

Published online: 2 August 2018

(C) The Author(s) 2018

\begin{abstract}
Scientific epistemology is a topic that has sparked centuries of philosophical discourse. In particular, understanding the role that scientists play in the creation and perpetuation of scientific knowledge is a subject that continues to be hotly debated. A relative new-comer to scientific epistemology is the field of virtue epistemology, which positions knowledge creation as integrally linked to specific character traits held by the scientist. Positioning scientific research as a distinct practice, virtue epistemologists strive to understand what virtues foster robust knowledge creation. Examinations of current scientific virtue epistemology, however, reveal how framings of "the scientist" tend to be highly individualistic and position the individual scientist as an actor with a high level of agency and autonomy. Such approaches, while following more conventional scientific epistemology discourse, contrast significantly with a growing body of social science literature that emphasizes the group nature of scientific research and education. This paper makes use of this social science literature to critically examine current deficits in narratives of scientific virtue epistemology. It highlights the need for the prioritization of virtues that enable scientists to work and learn in social environments through social processes. In particular, it discusses how the virtue of docility, best understood as being "open to learning", is a key virtue for training new scientists and for establishing robust processes of knowledge creation. By identifying current deficits in the manner in which science is taught, it demonstrates the considerable epistemic consequences of training scientists who do not embody docility in all aspects of their research activities. The paper concludes by discussing how docility
\end{abstract}

Louise Bezuidenhout

louise.bezuidenhout@insis.ox.ac.uk

1 Institute for Science, Innovation and Society, University of Oxford, Oxford, UK

2 Steve Biko Centre for Bioethics, University of the Witwatersrand, Johannesburg, South Africa

3 Center for Theology, Science and Human Flourishing, University of Notre Dame, Notre Dame, USA 
may be considered a key factor in an alternate understanding of the current reproducibility crisis in modern science.

Keywords Virtue epistemology $\cdot$ Science $\cdot$ Ethics $\cdot$ Docility

\section{Introduction}

Understanding the role that scientists play in the creation and perpetuation of scientific knowledge is a subject that continues to be hotly debated. A relative newcomer to scientific epistemology discussion is the field of virtue epistemology, which positions knowledge creation as integrally linked to specific character traits held by the scientist. By doing this, virtue epistemologists strive to understand what virtues foster robust knowledge creation.

However, examinations of current scientific virtue epistemology reveal how framings of "the scientist" tend to be highly individualistic and position the individual scientist as an actor with a high level of agency and autonomy. Such approaches, while following more conventional scientific epistemology discourse, contrast significantly with a growing body of social science literature that emphasizes the group nature of scientific research and education. This paper draws on this social science literature to expand discussions in scientific virtue epistemology by highlighting the need for the prioritization of virtues that enable scientists to work and learn in social environments through social processes. In particular, it discusses how the virtue of docility, best understood as being "open to learning", is a key virtue for training new scientists and for establishing robust processes of knowledge creation. By identifying current deficits in the manner in which science is taught, it demonstrates the considerable epistemic consequences of training scientists who do not embody docility in all aspects of their research activities. The paper concludes by discussing how docility may be considered a key factor in an alternate understanding of the current reproducibility crisis in modern science.

The structure of the paper is as follows. In the second section, we discuss a recent trend that connects virtue epistemology to issues in philosophy of science, but we also emphasize the limitations of this trend by highlighting the notable contribution of social studies of science, especially when the communal dimension of science is concerned. Subsequently, we provide a primer for the virtue of docility. In the fourth section, we highlight the possible roles of docility in several aspects of the practice of science. Based on the third and fourth sections, we then draw a few lessons for science pedagogy. Finally, we show through an example how the lack of cultivation of docility can lead to serious epistemic issues which can be easily connected to the present replication crisis in science. 


\section{Virtue Epistemology and Scientific Epistemology}

Scientific epistemology, as the study of scientific knowledge creation, is a topic that has sparked centuries of philosophical discourse. Within these discussions, virtue epistemology has recently emerged to challenge scientific analytic epistemology (Stump 2007). This section explores the emergence of virtue epistemology and how it has come to be part of discussions on scientific epistemology.

Virtue epistemology offers an interpretation of knowledge creation that intrinsically links the creative process to the specific character traits held by the scientist. In so doing, some virtue epistemologists (e.g. Zagzebski 1996) draw heavily on the long-standing virtue ethics tradition, making use of the notion of "virtues" as integral character traits that contribute to epistemic activities. While definitions of virtue - and the classification of virtues - may vary considerably, virtue epistemologists agree that virtues are either necessary or at least central to the formation of knowledge. Thus, knowledge is a justified true belief through the enactment of (intellectual) virtues. Similarly, virtue epistemologists all agree that virtues are excellences and that intellectual virtues are cognitive excellences that aid the achievement of specific goods.

Virtue epistemologists adhering to the Aristotelian tradition are generally known as 'responsibilists'. As Battaly (2008) reports, virtue responsibilists begin with the intuition that an agent is intellectually virtuous because of some active features of agency including motivations, actions, and habits for which (s)he is ultimately responsible ${ }^{1}$. In a very broad sense, intellectual virtues are acquired traits of intellectual action and motivation, and they emphasize the fact that a theory of knowledge should have a structure similar to the one of a moral theory - in particular a virtue theory. As a result, the majority of virtue epistemology discussions have focused on the individual scientist as an actor with a high level of agency and autonomy. 'Traditional epistemology' is best understood as grounded in a 'belief-based' approach (Battaly 2008; Greco and Turri 2011), wherein 'belief' is the most fundamental unit of analysis. By contrast, virtue epistemology is 'agentbased' and analyzes knowledge in terms of the characteristics of the agents. This represents an attempt to address the marginalization of the individual from traditional epistemology and to represent alternative narratives of knowing (see in particular Battaly 2008).

A coherent virtue epistemology account of scientific knowledge production marks a departure from more "traditional" philosophy of science. Indeed, the focus on linking the characters and actions of scientists in the production of scientific knowledge stands in contrast to more prevalent positivist accounts of scientific research and data production. Nonetheless, such connections are far from being

\footnotetext{
${ }^{1}$ This is in contrast to the reliabilists that represent intellectual virtues as "a quality bound to help maximize one's surplus of truth over error" (Sosa 1991: 225). In particular, Sosa thinks about virtues not in terms of the Aristotelian tradition, but in terms of faculties, and if intellectual virtues are some sort of excellences, then intellectual virtues would be well-functioning faculties including sense perception such as vision. In other words, according to Sosa, virtues and faculties are basically synonyms. Therefore, knowledge is a true belief out of a well-functioning and reliable faculty. The name 'reliabilists' derives exactly from the focus on virtues as 'reliable faculties'.
} 
new. An examination of the literature reveals that - though unsystematically - many philosophers of science have made connections between character traits and certain important philosophy of science issues. For instance, in The Logic of Scientific Discovery ([1959] 2002) Popper mentions that corroborations require sincere attempts to refute theories. 'Sincerity' may be interpreted as 'sincere attempts to discover the truth', which suggests an emphasis on a virtue-based language. Another example comes from the work of Duhem ([1906] 1954). He argues that sometimes evidence is insufficient to choose among competing theories (i.e. the problem of under-determination), and that the appeal to logic or other well specified rules would not be decisive. In response to this conundrum, Duhem introduces the concept of 'good sense' to refer to a sort of intuitive reasoning ability that can aid the scientist to resolve such indecision.

The work of Duhem, Popper, and others set the stage of the more recent discussion about virtues and science and led subsequent philosophers to connect Duhem's notion of 'good sense' to virtue epistemology (Zagzebski 1996; Sosa 1991). Stump's reconstruction of Duhem's notion of 'good sense' (2007) was the first attempt to connect philosophy of science and virtue epistemology. His article continues to fuel philosophical debate (Ivanova 2010, 2011; Kidd 2011; Fairweather 2012; Ivanova \& Paternotte 2013) about what virtues are necessary for excellence in science.

The challenge to identify virtues necessary for scientific practice has recently been taken up within the scientific community, and a number of groups have employed social science techniques to identify a "list of virtues" not dissimilar to earlier codes of scientific conduct. For instance, Pennock (2017) has elaborated a list of virtues that are deemed important by American scientists. By means of a quantitative analysis, he has been able to create a 'rank' of virtues in science by importance, where the 'importance' is assumed to be related by the contribution of a specific trait to the construction and reliability of scientific knowledge. The virtues identified, it must be recognized, are all associated with intellectual discovery rather than the communal nature of scientific research.

In relation to such studies it is important to recognize that such accounts of virtues in scientific practices struggle to account for an issue also observed in social studies of science - that a vicious agent could be epistemically successful as well (see, for instance, Paternotte and Ivanova 2016). History abounds with narratives of vicious individuals who display excellence as science researchers. For this reason, a few authors have tried to distinguish different ways of being good or being worth of praise, and to show that being a successful scientist does not necessarily mean being a good scientist.

For instance, Jason Baehr defined (intellectual) virtues “ "as personal intellectual excellences' or as traits that contribute to their possessor's 'personal intellectual worth" (2011: 89). Baehr distinguishes between different dimensions of being 'worth' (moral, aesthetic, spiritual, etc), and in the case of intellectual worth the idea is that we admire a person because of his/her intellectual abilities and orientations towards epistemic goods. In other words, Baehr assumes that there is a way of being good qua person that is distinctively intellectual, while other virtue epistemologists (e.g. Zagzebski) think that there is only one way of being good and 
this may also have epistemic consequences. Baehr elaborates a notion of intellectual virtues as "a character trait that contributes to its possessor's personal intellectual worth on account of its involving a positive psychological orientation towards epistemic goods" (Baehr: 102). In this way, virtues are not necessary for knowledge (though they are important ${ }^{2}$ ), and hence the existence of vicious individuals being epistemically successful does not constitute an objection to the virtue epistemology programme applied to scientific research.

\section{Learning from Social Studies of Science}

Despite the evolution of scientific virtue epistemology, it is important to recognize that descriptions of scientific virtues continue to be highly individualistic. By focusing on individual intellectual endeavours, they downplay the importance of communal practices, social interactions and extended cognition that characterize modern science. Little is said about other vital components of the epistemic practices of modern science such as how scientists work in groups, collaborate and share. As such, current virtue epistemology accounts continue to be at odds with social studies descriptions of scientific research such as social construction (Latour and Woolgar 1979: 12), social production (Lynch 1985: 56), social structure (Crane 1969: 336) and social categories (Traweek 1988: 162).

Ethnographic accounts of science reveal the complex and multifaceted nature of modern scientific research (Latour and Woolgar 1979; Traweek 1988; Rabinow 1996, and so forth). In the highly social world of laboratory research, scientists rarely - if at all - work alone to produce reproducible and reliable data. Furthermore, daily scientific activities also include collegial interactions and contributions to the coherent education of future scientists through formal and "hands on" training. Moreover, in terms of knowledge production modern scientists are involved in highly complicated cycles of credibility (Latour and Woolgar 1979) that mediate how, when and why they engage with the (online) global scientific community. As the authors suggest, a strong motivating factor for engaging in a global community exists, because scientists need each other in order to increase one another's production of credible knowledge and data (Latour and Woolgar: 202-203). This mutual need fosters a dynamic wherein scientists are continuously moving into new projects and problem areas in order to gain the most reward for their credibility. This cycle and fluctuation between projects, areas of expertise, and credibility supports the production of scientific research and knowledge.

Such descriptions of scientific research call into question current virtue accounts of science for a number of different reasons:

\footnotetext{
${ }^{2}$ Intellectual worth related to character traits "makes a salient contribution to what we might call the 'evidential situation' of the person in question, meaning that it largely determines either the content of the person's evidence or how the person handles or regards this evidence" (2011: 82). In other words, on the basis of the same data, different character traits may make scientists see different kinds of evidence - a virtuous scientist is more reliable.
} 
1. The majority of these accounts focus solely on the data production aspect of scientific research and marginalize the social and pedagogical elements of successful science

2. These accounts rarely include virtues relating to the tacit nature of laboratorybased scientific research (Collins 2001)

3. Accounts tend to focus on individual interactions and not on science as a group activity in which the social collective must be considered the fundamental unit of successful science

Such observations challenge current virtue epistemology discussions, and highlight the deficit of attention paid to the learning traditions, practices and social conventions of scientific research. In particular, such observations draw attention to a key element of scientific epistemology - that the creation of knowledge is not limited to the individual scientist's interactions with data, to models (Weisberg 2013) or theories, but rather with the learnt traditions that enable them to produce, disseminate and recombine datasets.

\section{A Case for Docility}

An examination of the ethnographic descriptions of scientific research highlights this oversight - that learning to be a scientist is a process of socialization. For the purpose of the article we define socialization as two interlinking areas of activity. First, scientific research is a group activity in which lone working is highly discouraged (and often impossible). Second, learning to work within these groups involves multifaceted educational interactions. While these two areas of socialization are not unique to scientific research, they are highly prominent and integral to all epistemic activities. Thus, it is feasible to suggest, they involve the cultivation of specific virtues. However, it is difficult to establish such a list a priori. Instead of context-free lists of virtues describing an idealized type of scientist, we must ask what virtues enable individuals to develop as a scientist in situ. Thus, it becomes important to investigate what virtues are enabling scientists to learn to be scientists. As we will show, a focus on docility is required to understand the interactional process of learning, since it is a virtue for which socialization is fundamental.

\section{Docility as a Key Epistemic Virtue}

What virtues account for learning to work as a scientist? What virtues enable science students to learn intelligently - from data, peers and mentors? Such questions lead us to examine a virtue that is often overlooked in philosophical discourse - the virtue of docility. Indeed, for those not embedded in virtue traditions the term docility can often be pejorative - suggesting a lethargic and submissive person who blindly accepts what is told to them, or one too submissive to power

\footnotetext{
${ }^{3}$ The term tacit knowledge came to prominence in science through the work of Harry Collins, who emphasized the acquisition of these knowledge types as key in the successful enactment and reproduction of practical scientific activities (Collins 2001).
} 
structures. Nonetheless, in Western virtue tradition (as informed by theology and philosophy), docility is the openness to learn what is being taught. Importantly, the virtue of docility also embodies a critically reflexive examination of what is taught.

In the scholastic tradition, it is difficult to understand the virtue of docility (docilitas) without mentioning the cardinal virtue of prudence (prudentia). The virtue of prudence is concerned with directing cognition of reality turned into particular matters of action (Aquinas 1948), or the right seeing of reality so that one chooses actions in accordance with how things are. Docility is an integral part of prudence because one who is teachable is able to learn how to interpret how one should act.

Docility shifts the educational focus away from the teacher who knows something to the learner who wants to know. Indeed, docility "implies the aliveness, the eagerness of the knower" (Schall 2016: 180), and it is not only about learning information but also about learning how to act well. Being docile is being willing to "listen to what is revealed to us. Only when we are first docile, teachable, taught do we really begin to think" (Schall 2016: 191). Thus, the virtue is a posture of openness to receiving knowledge being given by an instructor.

A docile attitude also means that the student must first start with a sense of wonder and a desire to find answers. What is meant here is that the student must have a desire to learn and a fascination with what is being taught. This can be connected to what some virtue epistemologists would call 'desire for truth' or 'epistemic conscientiousness' (Montmarquet 1992; Zagzebski 1996). The sense of wonder and desire for truth stem from an awareness that there are things that one does not know and a desire to seek answers from others. Being truly teachable "implies not merely that we have the capacity to know from our nature, but that we also, from within our individual being, desire to know and do something about acquiring knowledge of what we know we do not know" (Schall 2016: 179).

A necessary part of docility is a keenness to be instructed by others and a desire to obtain true knowledge (Pieper 1985: 225). Docility "is the kind of openmindedness which recognizes the true variety of things and situations to be experienced and does not cage itself in any presumption of deceptive knowledge" (Pieper 1956: 15). Open-mindedness here should not be read as a mere avoidance of prejudice, but rather it is a posture of openness to all that another can teach, based on their prejudice and experience. There has to be a posture of open-mindedness that is akin to a desire to know and learn. What we have seen above is that the docile student is internally motivated to find the truth of the world being taught.

While a considerable focus must be on the posture of the student in learning interactions, it is important to note that true enactment of docility requires a twoway relationship between student and teacher. Docility in teachers enables them to learn from their interactions with students, and to question what they are teaching, how and why. The teacher (and the student as well) exemplifies docility by remaining humble and open. A classic example of this is that while focusing on the docile instructor, Socrates exemplified docility by admitting that he did not know anything (e.g. Plato 1997). Moreover, docile teachers recognize that while the willingness to know is the one thing that we cannot 'give' to someone else, ... we might be able to inspire him or even prod him to know himself" (Schall 2016: 178). 


\section{Docility as a Part of Prudence}

The importance of docility as a virtue itself comes within the context of it being an integral part of prudence by perfecting and being perfected by it.

First, docility as an openness to being taught assists individuals in navigating the infinite variety of daily actions, which is something that pertains to prudence as well. To Aristotle, the virtue of docility assists individuals not only to learn by moral rules or precepts, but to learn the that and the because of moral action, and to live well by observing and emulating other prudent and wise people (Kristjánsson 2007: 99-113; Hursthouse 1999). Moral and social expertise as being "best gained through a novice-to-expert approach" is also an approach encouraged by modern psychology (Narvaez 2010: 171).

Next, prudence and docility are closely linked because of their situational aspect. Such a contextual nature of prudence and docility consists in knowing when to follow rules and procedures and when to deviate from them. An ethics that relies too heavily upon rules becomes casuistry which necessarily deflates into a 'science of sins' instead of a 'doctrine of the virtues' (Pieper 1956: 30). It is through the emulation of the teacher that the docile student learns how to act in a variety of situations, which usually exceeds the bounds of what rules by themselves are able to account for. Rules are not the ends of ethics and education, but rather a means.

Thus, docility is not a stand-alone virtue, and it plays a key role in the development of prudence and right situational action. The other side of docility, however, is to have a critical posture towards things being taught. There is a recognition that one should be open, but at the same time, at some point, one must learn to be appropriately critical of what one learns and who they learn it from. However, being docile is not simply to be critical but firstly open to the nearly infinite ways in which one might be required to act given the particulars of a situation.

Given the close connection between prudence and docility described above, why does docility require separate treatment from prudence? In one sense, based on the medieval theology and philosophy on which this conception of prudence draws, docility cannot be talked about in a robust way without putting it in the context of the cardinal virtue in which it seeks to perfect. On the other hand, prudence and docility are separate virtues as they serve different purposes within the moral life. Prudence is concerned with discerning means towards ends. This is not the case for the virtues that are 'integral parts' that make up prudence. Docility perfects habits of education, shrewdness (solertia) perfects our habits of quick and clear decision making, memory (memoria) perfects habits of recollection of the past for prudent discernment and action in the present. It also plays a fundamental role in learning from others.

If one critically unpacks the virtue of docility, its role mediating science as a communal activity should be clearly evident. Indeed, it underpins not only the "learning from others" nature of laboratory instruction, but also the fundamental communal nature of scientific data sharing and interactions. 


\section{Cultivating Docility in Scientific Research}

In this section, we examine how docility operates as a key virtue in perfecting the scientist when dealing with her disparate roles in scientific practice, such as a scientific community member, as a data producer, and as a contributor to global scientific knowledge. In contrast to more general social epistemology discussions that focus on inter-individual epistemic relations or epistemic communities, we are not looking at issues of trust and authority. Instead, we look at how a personal and individual character trait - docility - can enable individuals to interact more effectively within the realm of scientific activity.

\section{Docility and Data - Learning to "Read" Data}

The first area to consider is how scientists learn to interact with data. In considering this area of activity, it is important to recognize that the virtue of docility does not solely involve learning from individuals, but also learning from traditions and texts. True docility and prudence means that one should be open to teaching from a number of sources. Such observations are of key importance for scientific research. Indeed, at the core of the scientific endeavour is the continual objective and critical (skeptical) examination of existing data. Scientists have long been encouraged not to take both their own data or that of their peers at face value, but to critically interrogate it in terms of how it was produced, and how it fits in with other data available. Objectivity is recognized as a fundamental aspect of scientific practice.

The term "objectivity" dates to the mid-19th century, replacing what Daston and Galison call a "truth to nature" (2010: 55 - 58). The rise in objectivity reflected a turn in scientific practice that now served to restrain scientists from subjectively imposing their own projections onto the data they produced. In the 20th century, the understanding of objectivity was elaborated to incorporate what Daston and Galison call "trained judgement" (2010: 309) - where it was recognized that scientists needed to combine their mechanical depictions of data with a skilled interpretation that depended on professional training.

This combination of skill and mechanical excellence is further reflected in discussions about norms in science. Famously, Robert Merton included "organized skepticism" as one of his central norms of science ${ }^{4}$. By this he suggested,

"He [the scientific investigator] does not preserve the cleavage between the sacred and the profane, between that which requires uncritical respect and that which can be objectively analyzed" (Merton 1973: 265)

By this, Merton clearly highlights the responsibility that scientists have for not taking data at face value, or to assess it under the influence of the "particular dogmas of church economy or state" (Merton 1973: 265) .

Respect not only for data, but for the cultivation of docility through an engaged yet critical - attitude to it, pervades scientific pedagogy. Science students are taught

\footnotetext{
${ }^{4}$ In his seminal book, Merton (1973) identified four key norms that he proposes describe scientific culture: communalism, universality, disinterestedness and organized skepticism. While these norms continue to be debated and adjusted, the prominence of organized skepticism in scientific investigation is rarely questioned.
} 
key tools in how to read papers, to assess data and to engage with research in their field. Many universities have dedicated courses and/or literature to instruct students on how to cultivate an effective style of reading papers and interacting with data ${ }^{5}$. In so doing, they are instructed in practices that foster the virtue of docility - being open to the data presented to them, but engaged and suitably critical of it so as not to accept it at face value.

The cultivation of a docile approach to data is demonstrated by a quote from a neuroscience graduate student in a recent publication by Pain (2016, no page number),

"[I]f the authors' research is similar to my own, I see if their relevant data match our findings or if there are any inconsistencies. If there are, I think about what could be causing them. Additionally, I think about what would happen in our model if we used the same methods as they did and what we could learn from that. Sometimes, it is also important to pay attention to why the authors decided to conduct an experiment in a certain way. Did the authors use an obscure test instead of a routine assay, and why would they do this?"

This message is more concisely summarised by a quote by scientist Michael Specter, who advises individuals to: "Be skeptical. But when you get proof, accept proof" 6 .

\section{Docility and Experimentation - Learning to "Do Science"}

Another key element of being a scientist, unsurprisingly, is being able to work within a laboratory - to conduct experiments, collect and analyze data, and contribute to the day-to-day running of the laboratory. In addition to understanding the theoretical basis of experimentation, scientists need to cultivate tacit knowledge (Collins 2001), namely, the uncodified knowledge that is difficult to transmit solely via written or verbal instructions. In practical terms, this relates to the skills necessary to conduct experiments, understanding how to use a protocol, and how to troubleshoot unforeseen circumstances.

Ravetz (1971: 100) expands on this aspect of science by saying that "it is only in the training of research students in science that the craft character of scientific work is now explicitly recognized, and with it the importance of learning how to sense the presence of pitfalls". Teaching students how to work in a laboratory thus requires a balance between too much and too little guidance. Students need to learn from examples, but also be taught to critically engage with the routines they are learning. Again, Ravetz (1971: 100) elaborates on this by highlighting that "[r]esearch supervision itself is a craft, the most subtle and demanding sort of teaching".

\footnotetext{
5 A few examples include the excellent guide by Rice University found at http://www.owlnet.rice.edu/ $\sim$ cainproj/courses/HowToReadSciArticle.pdf and the University of York's guide/course description https://www.york.ac.uk/media/biology/documents/careers/critical_reading_handout.pdf (both accessed 15/02/2017).

${ }^{6}$ Taken from Jennifer Raff's LSE Impact of Social Science blog http://blogs.lse.ac.uk/ impactofsocialsciences/2016/05/09/how-to-read-and-understand-a-scientific-paper-a-guide-for-nonscientists/ (accessed 15/02/2017).
} 
Therefore, success in the practical aspects of producing data requires an active docility that enables scientists to learn from their peers and mentors while not taking the content of these interactions for granted. Docile students will be open to learning how to work from protocols in a responsible and efficient manner, but also critically question why they are performing each step. Indeed, as each step of a protocol has a theoretical underpinning (e.g. why is solution A added to solution B? What is the chemistry supporting such a step?), docile students must be continually aware not only of the ultimate purpose of the protocol, but also how each step facilitates the achievement of the goal. Simply reproducing a protocol, or obtaining results that were expected is not enough.

A key element in learning to work in the laboratory also involves being open to criticism and comments. Indeed, as Ravetz comments: "developing scientists of promise - or competent scientific manpower - depends on being allowed to fail, but being helped to recover" (Ravetz 1971: 100). In such situations, being docile - and thus teachable - involves being both involved and being humble in the situation at hand.

\section{Docility and Social Interactions: Learning How to be Part of a Group}

In a laboratory and across networks where researchers are working on the same problem, informal communication (Crane 1969: 336) can be considered as a mode of learning found among peers in scientific settings.

Things communicated in this capacity include (but are not limited to) discussing research findings, research-in-progress, and research techniques with peers and mentors. Informal communication is a learning activity related to docility in that these communications take place when the learner wants to know something. While working on the same problem, both scientists will have varying degrees of knowledge or experience with that problem. In creating knowledge about this problem area they are both learning, even when one may be the more experienced individual. In an informal setting the learner plays an active role in the act of knowledge creation and stands in stark contrast to the pejorative idea of a docile, submissive person. Furthermore, this mode of learning provides evidence for docility as a two-way relationship between student and teacher ${ }^{7}$ where the right seeing of the world (and the data) in terms of knowledge creation has the potential to result in joint publications.

\section{Docility and Communal Norms: Learning the Rules}

There is a considerable amount of literature about the normative culture of science. Indeed, the emergence of scientific ethics and global discussions about the responsible conduct of science are increasingly drawing attention to the need to

\footnotetext{
7 Crane (1969: 338) refers to moderate producers and aspirants as individuals who have fewer publications and high producers as those who have the most publications in the problem area of research. In the context of learning and sociable-ness, these two groups are analogous to students and teachers, where those with the most publications (high producers) will have the most to offer in the informal communication.
} 
identify norms and values to identify responsible research. In response to this movement, there has been an increasing amount of ethics oversight for scientific research. In the increasingly regulated milieu of modern science, this often takes the form of research ethics assessment, codes of conduct and punitive actions for misconduct such as falsification, fabrication and plagiarism.

Scientists thus increasingly have to navigate this complex ethical, legal and policy-governed space. It is tempting to assume that by "following the rules", they can act in accordance with community norms. However, considerable literature details instances of ethical dilemmas, conflicting expectations and wicked problems (such as Bezuidenhout 2015; Kornfeld 2016) that challenge scientists' interpretation of ethical behaviour. In order to successfully conduct research in this complicated milieu, it is thus vital that scientists exhibit docility in their willingness to learn from others. Prudence (and thus docility) is concerned with a right estimate about matters of action and their multiple facets. No one can sufficiently consider all of the ways one should act given particular circumstances, and finding exemplars and advisors considerably improves ethical action.

Docility offers an alternative to a reliance on rules, codes and regulations by fostering a critical engagement that is based on following the examples of others. Part of having prudence and docility is knowing when to follow rules and procedures and when to deviate from them. The docile student learns how to act in a variety of situations, a variety that exceeds the bounds of what rules by themselves are able to account for. Rules are not the ends of ethics and education, but rather the means.

\section{Docility and Scientific Training}

In an ideal form of scientific pedagogy, docility is fostered within science students in all areas of activity. Thus, students are taught to be open to learning, and critically engaged in the process of learning, when they learn to engage with data, conduct experiments at the bench, and interact with the scientific community. It is critical that cultivating docility in these different areas is not compartmentalized, but rather structured in a way that facilitates students to employ the same open attitude regardless of their activity.

This engaged interpretation of docility echoes a game proposed by Collins (1985). In the game students are presented with a list of instructions about the continuation of the sequence of actions (such as a protocol). The student has to misunderstand the instructions as many times as possible so as to reach a different continuation. The student must interpret the awkward continuation as a reasonable response to the rules provided so far (Collins 1985: 13). The object of the game is to show that "rules do not contain the rules for their own application" (Collins 1985: 14). Such teaching experiments can be seen to actively stimulate docility, by getting students to critically engage in why they are applying the rules that they do - and not to assume that these rules are either absolute, or even right.

It is only through active engagement - and proper instruction - in both the theoretical and social aspects of modern scientific research that students can emerge 
as effective scientists able to contribute to the epistemic goals of research. This raises an interesting consideration that concerns three key points:

1. Areas of learning in science are highly disparate and involve different styles of teaching (and engaging)

2. Docility as a virtue is not widely recognized in science pedagogy

3. Docility is stimulated differently in different areas of learning

Thus, effective science education involves the cultivation of docility. In the section below we critically examine training for docility in modern scientific education. We will highlight how the compartmentalization of the areas of learning identified above lead to problems in cultivating docility amongst science students. In particular, we will emphasize that the prioritization of docility in some areas over others have long-term implications for the education of epistemically robust scientists and the data they produce.

\section{Challenges Inherent in Current Pedagogical Approaches}

Traditional approaches to scientific pedagogy make distinctions between two loci of instruction, namely, the formal instruction in classrooms, and the controlled learning of undergraduate practical sessions. Students progressing to graduate level and beyond subsequently receive training from informal, peer-driven learning interactions occurring in the laboratory during graduate training. Little, if any, connection is made between these two highly disparate sites of learning - something that we demonstrate to be highly problematic.

Within classroom settings students are regularly exposed to competing knowledge claims, contradictory data evidence and a plethora of theoretical interpretations. Similarly, they are inducted into the historical tradition of their scientific discipline through the discussion of key scientists and discoveries. Such an approach requires students not to take data at face value, but to critically examine any data that is presented to them ${ }^{8}$. In this way, classroom teaching fosters a critical engagement in terms of dealing with data. In this way, we can see how docility can be fostered, as a "kind of open-mindedness which recognizes the true variety of things and situations to be experienced and does not cage itself in any presumption of deceptive knowledge" (Pieper 1956: 15).

In contrast, students are instructed very differently in their practical sessions in which they acquire the tacit skills necessary to conduct laboratory work. These sessions focus on the acquisition of basic laboratory experience by the repetition of experiments under direct supervision. Importantly, within these sessions, all protocols used have been carefully pre-tested and evaluated for clarity and reproducibility. Thus, the key object of these sessions is to become familiar with the

\footnotetext{
8 A few examples include the excellent guide by Rice University found at: http://www.owlnet.rice.edu/ $\sim$ cainproj/courses/HowToReadSciArticle.pdf and the University of York's guide/course description https://www.york.ac.uk/media/biology/documents/careers/critical_reading_handout.pdf (both accessed 15/02/2017). Also Jennifer Raff's LSE Impact of Social Science blog http://blogs.lse.ac.uk/ impactofsocialsciences/2016/05/09/how-to-read-and-understand-a-scientific-paper-a-guide-for-nonscientists/ (accessed 15/02/2017).
} 
laboratory equipment and the physical practices of science, rather than to truly experience what constitutes laboratory-based research. Indeed, as research bench work involves the development and optimization of protocols, the adaption of working practices to suit the environment and resources available, and the coproduction of knowledge with peers, undergraduate laboratory training offers little in the way of insight.

These undergraduate practical instances often emphasize the following of instructions, rather than critical engagement. Thus, the most effective students are ones that follow instructions, rather than those that critically question why they are required to perform the steps detailed on the protocol. Such settings, it may therefore be argued, do not offer much scope for cultivating docility. Indeed, in order to encourage students to cultivate a docility of experimentation in these settings would require that they be pushed to critically engage with what each step in the protocol means and to understand why they are doing what they are doing. Successfully and meticulously following a protocol without critically asking why steps are being taken, and specifically the science behind it, is by no means a sufficient way to cultivate docility. It must also be recognized that such situations are unlikely to change rapidly. Many educators are hampered in the extent to which undergraduate students can experience laboratory bench work due to time and financial constraints 9 .

\section{Making a Bridge Between Compartmentalized Instances of Docility Cultivation}

Traditions of science pedagogy dictate that much of the tacit knowledge necessary for practical experimentation acquired by students, as well as their socialization and their integration into communities of research occur informally when they enter graduate laboratories. While this tradition of learning through 'doing and observation' is an important means of integrating scientists into the culture and practices of their individual laboratory, it nonetheless requires that the virtue of docility cultivated (or not) in undergraduate training is perpetuated and enhanced in these learning interactions.

\section{Inefficient Cultivation of Docility: Challenges for Reproducibility}

What implications does what has been said so far have for scientific epistemology and the production of robust scientific knowledge? Current structures of science education - and indeed, of scientific research itself - seem to foster situations of incomplete docility acquisition. Indeed, the traditions of teaching the practical

\footnotetext{
9 This is discussed by Baker and Verran (2004: 338) where they say: "As progress continues to be made in microbiology research, and the discipline expands to encompass bioinformatics, genomics and molecular biology, the costs that are associated with running valid, up-to-date laboratory classes are increasing. At the same time, science departments are facing budget cuts. Frequently, the first - and perhaps only - area targeted for significant cuts is the teaching laboratory. We are being asked to find new, less-expensive methods to educate an increasing number of students, while still providing a stimulating and relevant experience".
} 
aspects of scientific research would often seem to promote a vice of docility uncritical acceptance and submission - rather than the cultivation of the virtue itself. This contrasts strongly to the highly activated docility taught in relation to the use of data.

While individuals with robust characters would, of course, be able to use exemplars to identify the right course of behaviour in the laboratory and cultivate docility, such an assumption is dangerous to make. In particular, without guidance many scientists will persist in situations of incomplete docility, where they continue to be less critical of the protocols, routines and practices in play within the laboratory than they should. This is largely due to the submissive attitude they cultivate regarding the authority that these practices assume through being taught to them by others.

In order to demonstrate these concerns, we make use of a recent example from scientific literature. A 2017 paper published by William Conrad and colleagues in PNAS detailed the need for revising the accepted activity of the ESAT-6 protein in M. tuberculosis virulence. Below is a section from the abstract:

“... multiple studies have reported that recombinant ESAT-6 lyses eukaryotic membranes. We too find that ESX-1 of M. tuberculosis and M. marinum lyses host cell membranes. However, we find that recombinant ESAT-6 does not lyse cell membranes. The lytic activity previously attributed to ESAT-2 is due to residual detergent in the preparations. We report here that ESX-1-dependent cell membrane lysis is contact dependent and accompanied by gross membrane disruptions rather than discrete pores. ... Our findings suggest a redirection of research to understand the mechanism of ESX-1-mediated lysis" (Conrad et al. 2017: 1376).

Rather shockingly, the paper elaborates on how a flawed protocol that has been perpetuated through the field for a number of decades has given rise to an incorrect interpretation of the biological function of the protein ESAT-6. This has shaped a considerable amount of research in the field of tuberculosis research. Further in the text (Conrad et al. 2017: 5), the authors elaborate on this,

"[o]ur question to confirm and expand the model of ESAT-6 as a cytolytic, poreforming toxin took an unexpected turn when the serendipitous omission in a welldefined and widely used purification protocol led us to reexamine the biological function that had been widely attributed to this mycobacterial virulence determinant. Our experiments led us to reinterpret ESX-1's membrane lytic activity. We hope our findings will lead to a better understanding of this and of ESAT-6's biological function".

The presence of a detergent in the isolation of a protein suspected of having cytolytic functions must have raised at least some concern over the years. Nonetheless, the legitimacy that the protocol acquired - through being reported in a number of high-impact articles - led to its perpetuation through successive research projects. This, understandably, had significant epistemic consequences for both the field and for molecular biology more generally.

From the discussion on docility above, however, it is possible to suggest how such problems might have been offset. Were the individual scientists critically engaged in the protocols they were working from, and questioning of each step it is possible that this mistake would not have been perpetuated for so long. Indeed, by 
demonstrating the vice of passiveness, instead of the virtue of docility, these authors unquestioningly perpetuated a flawed methodology.

Such observations therefore offer an alternative narrative for the current "replication crisis" in modern science ${ }^{10} \cdot{ }^{[10]}$ Currently, there are many different reasons suggested for why scientific research is so unreproducible. These range from clear ethical misconduct - such as falsification, fabrication and plagiarism (Kornfeld 2016) - to issues relating to the current structures of science and traditions of publishing. In light of the former, pressure to publish, lack of in-lab replication, insufficient mentoring, and poor experimental design are often identified as key issues (Baker 2016). For the latter, selective reporting, poor peer review, unavailable metadata and poorly written methods are all key (Baker 2016).

Instead, we suggest that the epistemic crisis of non-replicability can at least in part be explained by a pervasive lack of docility within scientific communities. Current structures of scientific education are failing to train docile individuals that critically engage with the practice as well as the products of scientific research. Indeed, it strongly suggests a need to rethink how undergraduate students are taught the tacit skills of working in laboratories, and to scrutinize the informal learning practices of teaching graduate students in laboratories.

It is of critical importance to recognize that just because science students are instructed in the practice of docility in terms of data engagements, this does not automatically guarantee docility in the way they follow protocols or learn from their peers. Indeed, in order to truly unpack such observations, a considerable amount of empirical literature is necessary - but currently absent - for current discussions.

\section{Conclusion}

By drawing on disparate bodies of literature - from theology, social science and philosophy - this paper has offered an account of the virtue of docility in scientific research. In particular, it highlights how a pervasive lack of attention to the community-driven activities of scientific knowledge production have caused narratives of virtue epistemology to overlook key virtues necessary for the practice of science.

We strongly recommend a more sustained focus on the social and communal aspects of scientific knowledge production that look at group interactions and group-individual interactions as fundamental in the production of good scientific data and integral to replicable science.

\footnotetext{
${ }^{10}$ Evidence suggests that far fewer published experiments can be replicated than was previously thought - either by independent researchers or by the original researchers themselves (Schooler 2014). These concerns have been exemplified by publications such as John Ioannidis' 2005 succinctly titled paper, Why most published research findings are false. Highly publicized examples, such as the $40 \%$ reproducibility rate in psychology research (Open Science Collaboration 2015), and the even more shocking $10 \%$ in cancer biology (Begley and Ellis 2012) are widely touted as reasons for concern. Similarly, in a recent Nature survey of 1,576 researchers, more than $70 \%$ of respondents had tried and failed to reproduce another scientist's experiments, and more than half had failed to reproduce their own experiments (Baker 2016).
} 
Acknowledgements The authors were supported by the Templeton Religion Trust on the grant Developing Virtues in the Practice of Science.

Open Access This article is distributed under the terms of the Creative Commons Attribution 4.0 International License (http://creativecommons.org/licenses/by/4.0/), which permits unrestricted use, distribution, and reproduction in any medium, provided you give appropriate credit to the original author(s) and the source, provide a link to the Creative Commons license, and indicate if changes were made.

\section{References}

Aquinas, Thomas. 1948. Summa Theologica. Fathers of English Dominican Province transl. Notre Dame: Ava Maria Press.

Baehr, Jason. 2011. The Inquiring Mind. Oxford: Oxford University Press.

Baker, Monya. 2016. 1,500 scientists lift the lid on reproducibility. Nature 533: 452-545.

Baker, N., and J. Verran. 2004. The future of microbiology laboratory classes-wet, dry or in combination? Nature Reviews Microbiology 2: 338-342.

Battaly, Heather. 2008. Virtue Epistemology. Philosophy Compass 3(4): 639-663.

Begley, C.G., and L.M. Ellis. 2012. Drug Development: Raise Standards for preclinical practice research. Nature 483(7391): 531-533.

Bezuidenhout, Louise. 2015. Ethics in the minutiae: Examining the role of the physical laboratory environment in ethical discourse. Science and Engineering Ethics 21: 51-73.

Collins, Harry M. 1985. Changing Order. Beverley Hills: Sage.

Collins, Harry M. 2001. Tacit Knowledge, Trust and the Q of Sapphire. Social Studies of Science 31(1): 71-85.

Conrad, W.H., et al. 2017. Mycobacterial ESX-1 secretion system mediates host cell lysis through bacterium contact-dependent gross membrane disruptions. PNAS 114(6): 1371-1376.

Crane, Diana. 1969. Social structure in a group of scientists: A test of the" invisible college" hypothesis. American Sociological Review 34: 335-352.

Daston, Lorraine, and Peter Galison. 2010. Objectivity. Cambridge, MA: MIT Press.

Duhem, Pierre. [1906] 1954. The Aim and Structure of Physical Theory. Princeton NJ: Princeton University Press.

Fairweather, Abrol. 2012. Duhem-Quine virtue epistemology. Synthese 187(2): 673-692.

Greco, J., and J. Turri. 2011. Virtue epistemology. In Stanford Encyclopedia of Philosophy.

Hursthouse, Rosalind. 1999. On Virtue Ethics. Oxford: OUP.

Ivanova, Milena. 2010. Pierre Duhem's good sense as a guide to theory choice. Studies in the History and Philosophy of Science Part A 41(1): 58-64.

Ivanova, Milena, and Cedric Paternotte. 2013. Theory choice, good sense and social consensus. Erkenntnis 78(5): 1109-1132.

Kidd, Ian James. 2011. Pierre Duhem's Epistemic Aims and the Intellectual Virtue of Humility. Studies in History and Philosophy of Science 42(1): 185-189.

Kornfeld, D., and S. Titus. 2016. Stop ignoring misconduct. Nature 573(7618): 29-30.

Kristjánsson, Kristján. 2007. Aristotle, Emotions, and Education. Aldershot: Ashgate.

Latour, Bruno, and Steve Woolgar. 1979. Laboratory life: The construction of scientific facts. Beverly Hills, London: Princeton University Press.

Lynch, Michael. 1985. Art and Artifact in the Laboratory Science. London: Routledge and Kegan Paul. Merton, Robert. 1973. The Sociology of Science: Theoretical and Empirical Investigations. Chicago: University of Chicago Press.

Narvaez, Darcia. 2010. Moral Complexity: The Fatal Attraction of Truthiness and the Importance of Mature Moral Functioning. Perspectives on Psychological Science 5(2): 163-181.

Montmarquet, James. 1992. Epistemic virtue and doxastic responsibility. American Philosophical Quarterly 29(4): 331-341.

Open Science Collaboration. 2015. Estimating the Reproducibility of Psychological Science. Science, 349(6251). 
Pain, E. 2016. How to (seriously) read a scientific paper. Science. https://doi.org/10.1126/science.caredit. a1600047.

Paternotte, Cedric, and Milena Ivanova. 2016. Virtues and vices in scientific practice. Synthese. https:// doi.org/10.1007/s11229-016-1023-2.

Pennock, Robert. 2017. The Scientific Character Virtues: An Interdisciplinary Study 5-29-2017. http:// wcri2017.org/images/documents/1.\%20Monday\%20May\%2029,\%202017/5.\%205A-00/R.\% 20Pennock\%20-\%20The\%20scientific\%20character\%20virtues;\%20An\%20interdisciplinary\% 20study.pdf. Accessed 6 Sept 2017.

Pieper, Josef. 1956. Prudence. In The Four Cardinal Virtues. Transl. Clara Winston and Richard Winston, pp. 1-42. South Bend: Notre Dame University Press.

Pieper, Josef 1985. The Art of Making Right Decisions. In Problems of Modern Faith: Essays and Addresses. First American Edition. Transl. Jan Van Heurch, pp. 219-30. Chicago: Franciscan Press.

Plato. 1997. Gorgias. In Plato: Complete Works, ed. John M. Cooper, transl. Donald J. Zeyl, 791-869. Indianapolis: Hackett.

Popper, Karl. [1959] 2002. The Logic of Scientific Discovery. Abingdon: Routledge.

Rabinow, Paul. 1996. Making PCR: A story of biotechnology. Chicago, London: University of Chicago Press.

Ravetz, Jerome. 1971. Scientific Knowledge and its Social Problems. Piscataway NJ: Transaction Publishers.

Schall, James V. 2016. Docilitas: On Teaching and Being Taught. South Bend: St. Augustine's Press. Schooler, Jonathan. 2014. Metascience could rescue the replication crisis. Nature 515(7525): 9.

Sosa, Ernest. 1991. Knowledge in Perspective. Cambridge, UK: Cambridge University Press.

Stump, D.J. 2007. Pierre Duhem's virtue epistemology. Studies in History and Philosophy of Science Part A 38(1): 149-159. https://doi.org/10.1016/j.shpsa.2006.12.010.

Traweek, Sharon. 1988. Beamtimes and Lifetimes. Cambridge, London: Harvard University Press.

Warne, Nathaniel A. (Forthcoming). Forward on Shared Paths: Josef Pieper on the Importance of Common Language for Justice and Interdisciplinary Learning. Philosophy, Theology, and the Sciences.

Weisberg, M. 2013. Simulation and Similarity: Using Models to Understand the World. Oxford: Oxford University Press.

Zagzebski, Linda. 1996. Virtues of the Mind: An Inquiry Into the Nature of Virtue and the Ethical Foundations of Knowledge. Cambridge: Cambridge University Press. 